\title{
The Implementation of Mashups Web to Integrate Students Data and Service Announcement in a University Website
}

\author{
Fransisko Eko Sanaky \\ Magister Information Systems, \\ Faculty of Information Technology, \\ Satya Wacana Christian University \\ Diponegoro Street 52-60 Salatiga, \\ Indonesia. 50711
}

\author{
Eko Sediyono \\ Magister Information Systems, \\ Faculty of Information Technology, \\ Satya Wacana Christian University \\ Diponegoro Street 52-60 Salatiga, \\ Indonesia. 50711
}

\author{
Irwan Sembiring \\ Magister Information Systems, \\ Faculty of Information Technology, \\ Satya Wacana Christian University \\ Diponegoro Street 52-60 Salatiga, \\ Indonesia. 50711
}

\begin{abstract}
The purpose of this study is to develop a web application 'mashup' implemented to students data obtained from the existing system in Satya Wacana Christian University (siasat.uksw.edu), combine with faculty information system (ftiuksw.org), to give a new academic information system, without modify them. In order to develop mashup, there are several tools that can be used to help users with no programming background. However, in this research, mashup is developed by using conventional web programming techniques. The results of this study is a mashup that combines information obtained from student data and web content that combaines information obtained from student data and web content to give announcment to specific students.
\end{abstract}

\section{Keywords}

Mashups, RSS, REST, Students Data, Service Announcement

\section{INTRODUCTION}

Faculty of Information Technology (FTI) as a part of the Satya Wacana Christian University (SWCU) has several systems that are used as a service to students which can be accessed by the internet. SIASAT is a name of system used for course registration, viewing class schedules, GPA, bills and other things. In addition, FTI also uses website as a media to provide information to students. All information such as college activities, announcements, news and other things are informed through website (http://ftiuksw.org/).

The systems that mentioned above are separate system. Thus, to obtain required information students must access several systems. For example to find out the class schedule or participants in a class, students use SIASAT to obtain such information. Moreover, to know the information submitted by the faculty or lecturers, students acquire through the FTI website. The problem that appears is the student must search for information related to him/her such as Student Identification Number, the course name and the lecturer (where the student is registered) in any information presented on the separated website. This is difficult for students to obtain information such that.

The concept of integrating or combining some data or service into a new service has been there before. Portal as an example of web applications that combine or integrate data from various domains. Service-Oriented Archtecture (SOA) paradigm is also used to build new services. As part of a technology web 2.0, mashups can be used to integrate data and services into a new service [1]. Mashups can also functioned like SOA, as a service provider and use it as data sources, and can be accessed using a web interface. In some examples, mashups can be viewed as applications built using SOA [2]. Mashup and SOA have both similarities and differences. Zeets [3] describes mashups and SOA have similarities in terms of developing new services by combining two or more services. While the difference, SOA is made for a particular purpose and all services made are being used for that purpose. Whereas mashups, was designed to combine existing webs to give a compound information

The purpose of this study is to develop a web application 'mashup' by using data from SIASAT and FTI website, to create a service announcements that help students to acquire information related to him/her such as Student Identification Number, lectures are taken and its lecturer. By applying mashup, it can be developed an integrated system into a web or service that allows students to obtain information they need.

\section{LITERATURE REVIEW}

\subsection{Research Preview}

Study by Ozkan [4] use mashups to support the recruitment and selection process in admissions process at university. The study was conducted to explore whether social networking profile information is useful in the recruitment and selection process of students at the university. To get the answer, a mashup application was developed to find Social Network profile information through Application Programming Interface (API). The result, is an application that provide benefits for organizations in order to gain a competitive advantage. However, the information obtained by web can not be used as a reference in formal recruitment and selection. Additionally, an application should not be used to determine the final decision of student admission.

Gendarmi [5] developed a mashup web that combine information from different Social Libraries called Collabry. The information used is the combination from book metadata (eg. title, author and publisher) and user-generated information (eg. tag and review). 
Another study conducted by Kulathuramaiyer [6] developed a mashup web for digital journal. This study used data from an electronic journal called J.UCS. J.UCS has information such as authors and editors that also contains information about university, city and country. J.UCS data is integrated with Google Map API to display data in a map. Additionally, Google search API is also used to discover city names of universities with information in J.UCS data.

\subsection{Mashup}

The term mashup begins in the composition of the musical style that recording a song combined from various sources of song. As a web application, mashup is the combination of several services and data become a new service. Koschmider [7] define mashup as a web-based application that was developed by combining and processing sources of data online from third party that contribute form of data, presentation and functionality, online data sources refer to all types of data sources which are available in the Internet. Baig [8] mentions that mashup is an innovative technology for programmer and those who are not, who want to use various products and services that are available on web to create new products and services.

\subsubsection{Mashup Examples}

ProgrammableWeb provides various information links mashup and APIs that can be used for developing web mashup. There are several examples of mashups created for various purposes. ProgrammableWeb also categorize web mashup in a few categories such as maping, search, social, video, music, photo and others. Wong [9] also categorizes mashup in a few patterns such as aggregation, alternate User Interface (UI) and in-situ use, personalization, and focused view of data and real time monitoring. However in development can combine several categories become new service.

Data from ProgrammableWeb shows that mashup map is the example which many mashups was developed. HousingMaps is other example of map mashup that combine Google map and Craigslist, which provides information on rental homes apartments, and rooms. As the result, users can see the home rental information along with its location in google map. Pancardo [10] also developed a map mashup using Google Maps, Flickr and Yahoo Weather Service. The application is an information service to the public during disasters.

\subsubsection{Tipes of Mashups}

Mashups can be categorized in three types: Data Mashups, Consumer Mashups and Business Mashups [8] [11]. Data mashup combines several data sources of similar type in an interface. Examples of Data mashups is Skyscanner.com which combines data flights from several airlines.

Consumer mashups is the fastest growing type of mashups. Contrast to Data mashups, this style is combining different types Data sources in one interface. HousingMaps is an example of consumer mashups.

Enterprise mashups used to solve problems that exist in a particular business. Combining internal and external data as a data source. Zeets studied the use of mashup in supply chain management. Zeets stated that mashups can be applied in supply chain management on a supply chain process. The example given is the use of mobile applications to avoid traffic jams and bad weather.

Additionally, Sheong [12] also classify the type of mashups by how the use in building applications, which consists of
Mashup Application, that is a web mashup that provides all the functionality for users the other is Mashup Plugin that provides only a few parts of functions of existing web applications.

\subsubsection{Mashup Architecture}

Mashup architecture consists three entities that are physically and logically separated from one to another through the internet. As shown in Figure 1 Presentation / Interactivity layer as the interface (Web Browser). Web Services Layer as a liaison between the web browser to the data layer.

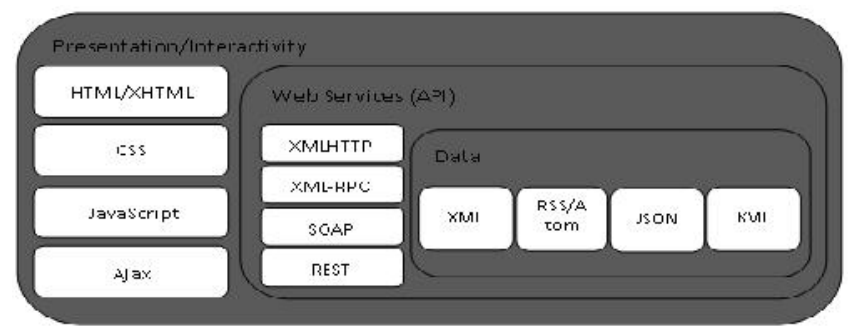

Figure 1. Mashup Architecture Layers

Wilkinson [13] also showed mashup architecture from an architectural viewpoint or where the process takes place which is mashup client- based and server-based. Client-based mashup is a process mashup that processed on the client browser where information is collected and displayed directly to the client. Instead server-based mashup, information is collected, analyzed, combined and modified be processed by the server and then sent to the client.

\section{METHODOLOGY}

To develop mashup can be used programming techniques in developing web applications and also can use several tools to develop mashups [14]. Commonly used tools to develop mashup based on user desires. Tools that can be used is the IBM Mashup Center, Intel Mash Maker, and Yahoo! Pipes. Chatti [15] states that there are two limitations when using mashup tools. First, the service is limited to some common data such as RSS and ATOM. Second, most existing tools are used only for companies that develop these tools.

Salminen [16] describes mashup can be developed with a few steps. First Selecting Data source. The selection can be based on several criteria such as reliability, accessible, data format, availability of documentation, the use of APIs and other terms. Phase two accessing Data source and Data handling. Data can be accessed via HTTP interface and used on a different programming model. Furthermore, Data need to be processed, filtered and may be converted into a common format and then stored into database mashups. Phase three creating mashup core functionality. After the source of Data in the appropriate format, application development logic is defined and programmable. Last phase debugging and testing. This phase testing during the development process and tested on several different browsers. The same Mashup development without tools is also described by $\mathrm{Yu}$ [17].

\begin{tabular}{|c|c|c|c|}
\hline $\begin{array}{l}\text { Selecting Data } \\
\text { Source }\end{array}$ & $\begin{array}{c}\text { Accessing } \\
\text { Data Source } \\
\text { and Data } \\
\text { Handline }\end{array}$ & $\begin{array}{l}\text { Create Core } \\
\text { Mashup } \\
\text { runctionality }\end{array}$ & $\begin{array}{l}\text { Jebuging anc } \\
\text { lesting }\end{array}$ \\
\hline
\end{tabular}

Figure 2. Mashup Development [16] 


\section{Result}

\subsection{Existing Working System}

SIASAT is a system used by students to get information about course registration, schedule of classes, study attendees, bills and others. SIASAT is an academic information system that can be accessed by students through internet. To access the system, a student has a password which is used only to access that student information. This system is used when a student want to do course registration and view course schedule. Faculty websites also used as a media to provide information from lecturers or faculty to students. Information in the form of changes in class schedules, counseling schedule, news and more. Website may contain information like NIM (Student Identification Number) and student names, course code and name, and also the name of the lecturer.

Problems in the current system announcements, students should find information related to their courses by looking at any information presented on website. It is difficult for the students to find information or announcements intended for a particular student.

\subsection{System Developed}

As mentioned above, the purpose of this study is to developed a web mashup by using data from SIASAT and website that are used as a media announcement to create new service announcements. The system is expected to help students in acquiring information related to her / him such as NIM (Student Identification Number) and names, courses and lecturers.

Figure 3 shows the architecture of developed system. There are two data sources used, the data obtained from university (SIASAT) and faculty website. SIASAT have data such as students, courses and lecturers. To access the data from university system, you can use service to obtain the desired data. Whereas faculty website data accessed by the url RSS Feed. In the system there is a database that function to store the url of RSS Feed and users who use system. After the data is obtained, the server will make the process of merging data then displayed on the client browser.

System developed has Search and Aggregation functions that can make the process of searching the student data obtained from SIASAT, then use it to find the information on the website.

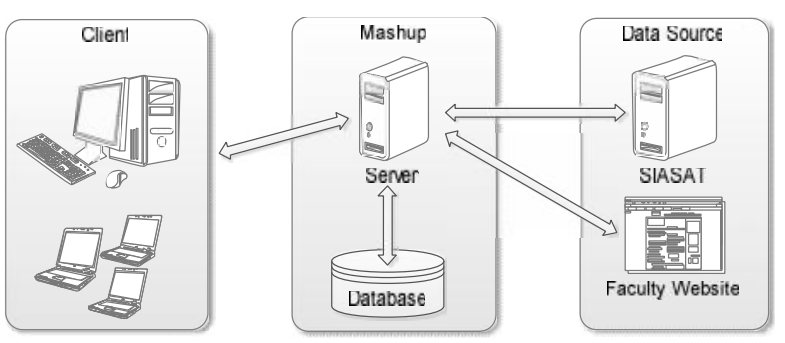

Figure 3. Architecture of System Developed

\subsection{Mashup Development}

\subsubsection{Selecting data source}

According to the system requirements, the required data are students, lecturers, courses, and RSS Feed. Students data, lecturers, and courses obtained from SIASAT. Figure 4 shows examples of data used by the system. This show an example a student's class schedule where there are few data required by the system such as courses and its lecturer. Moreover, the FTI website indicates there is some information that had similarities with the data obtained from the SIASAT.

Each data retrieved from both sistems were taken few attributes as a parameter that is used as the information wants to display. Students data, Lecturer and Course was obtained in JSON/XML. Table 1 show parameters used for each data required by system.

Table 1. Data Source

\begin{tabular}{|l|l|}
\hline \multicolumn{1}{|c|}{ Data } & \multicolumn{1}{|c|}{ Parameter } \\
\hline Mahasiswa (Students) & $\begin{array}{l}\text { NIM (Student Identification } \\
\text { Number), } \\
\text { Name }\end{array}$ \\
\hline Dosen (Lecturer) & $\begin{array}{l}\text { Code, } \\
\text { Nama Dosen (Lecturer name) }\end{array}$ \\
\hline Matakuliah (Course) & $\begin{array}{l}\text { Kode Matakuliah (Course Code), } \\
\text { Nama Matakuliah (Cource Name), } \\
\text { Dosen/ Lecturer (Lecture Code dan } \\
\text { Name) }\end{array}$ \\
\hline Website & $\begin{array}{l}\text { RSS atributes such as Title, } \\
\text { Description, Link, Guide and } \\
\text { others }\end{array}$ \\
\hline
\end{tabular}

4.3.2 Accessing data source and data handling Students Data, Lecturer and Course are internal data held by university. To be able to access that data, the system use services provided by the university. Service can be a web service or REST. Thus, the format of the obtained data can be XML or JSON. Whereas website accessible through url address to access RSS feeds. After the data accessed system will build variable to suit parameters on Table 1. It aims for displaying information to users

Table 2. Protocol

\begin{tabular}{|l|c|}
\hline \multicolumn{1}{|c|}{ Data } & Protocol \\
\hline $\begin{array}{l}\text { Students, } \\
\text { Lecturer and } \\
\text { Course }\end{array}$ & REST/SOAP \\
\hline
\end{tabular}

The services that is used only to access the data and not to change it. The privileges that can do by the system are grap the data Students, Course and Lecturers. The results of data retrieval from the students, the system will acquire the data in the form of Student Identification Number and student names, otherwise the system also gets that list of course taken by the students. Data from course obtained code and name of the lecturers who teach and also a list of other students enrolled in the same course.

\subsubsection{Creating core mashup funtionality}

Workflow system developed is shown in Figure 4. Initially, the system receives user input as keywords. The keywords are used by the systems to search students data, lecturers or course.

The next step, the system will make the process of retrieval data (Get Data) using the service in Table 2. Because there are two data sources used then process of collecting data is conducted for each service. The first service to process is take the data Students, Faculty and Course. The process undertaken includes: 
Data Source From SIASAT

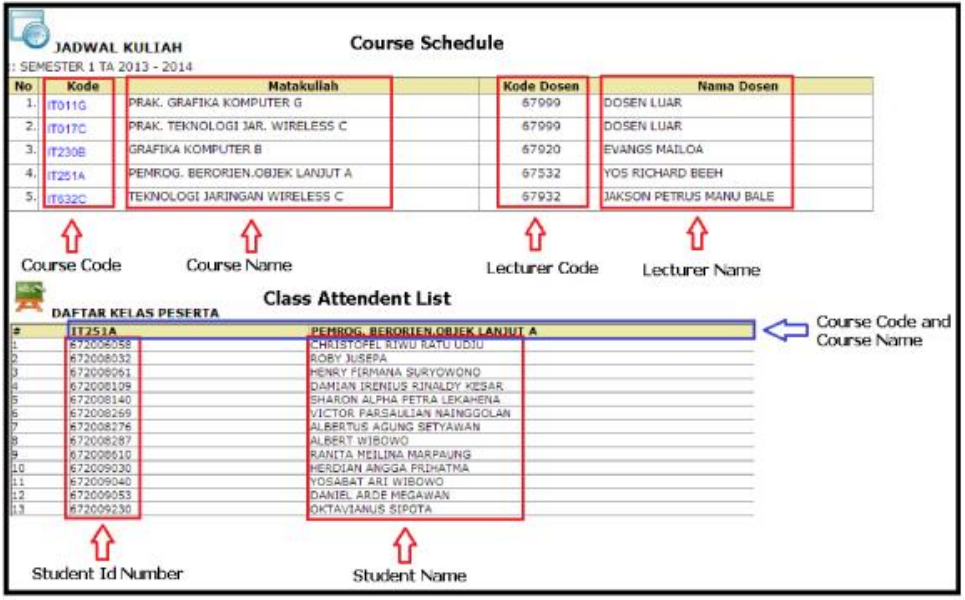

Data Source From Faculty Website

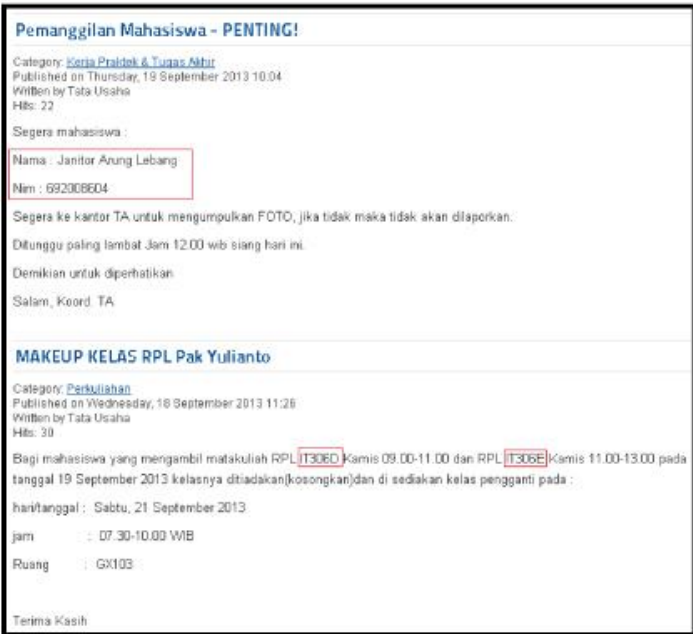

Figure 4. Data Source From SIASAT and Faculty Website (Before Mashup)

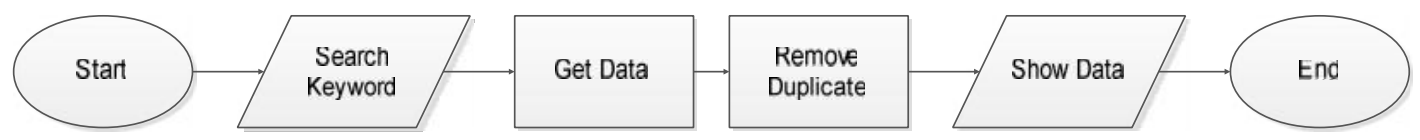

Figure 5. Workflow System Mashup

1) System receives a keyword from users.

2) System does a search Data of Student, Course and Lecturer using service to access SIASAT with keywords that entered.

3) If there is 1 data found, the system will take attributes of data as new keyword to search data on the website. Example, the data sought is a student, then attribute used as keywords are NIM (Student Identification Number), student name, course name and the lecturer.

4) Otherwise, if there are more than 1 records, the system will display the results of data sought to selected by the user.

The next step, system uses data from the previous process as a keyword to find information on websites where the content matches to the attributes of the data. Process undertaken includes:

1) System receives data from previous search.

2) System does a search on website by accessing url address RSS feeds that stored in system database.

3) Searching process conducted by comparing content of the website with the data from previous search.

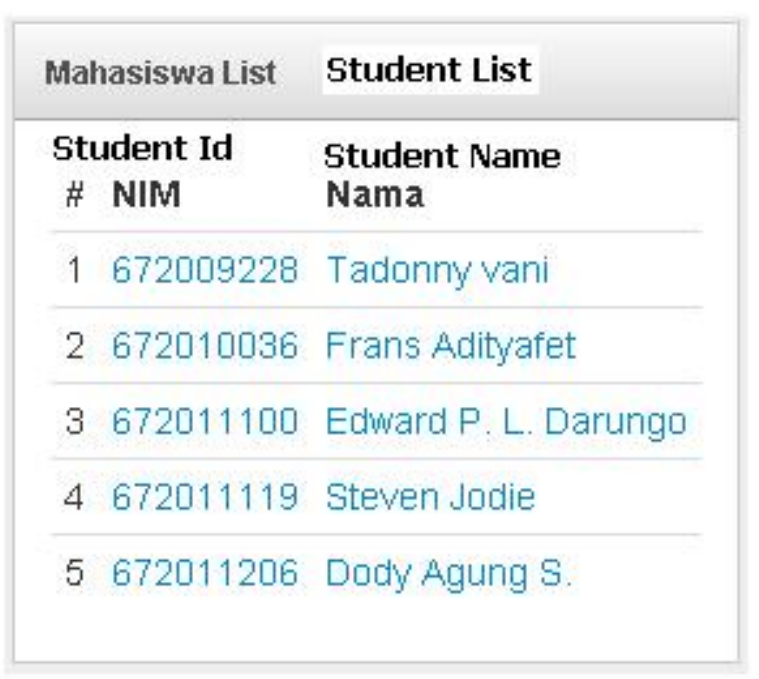

Figure 6. Search Result

4) If there is a data found, the system will receive data that consists of title, description and link.

After obtaining the data then system looks for duplicate data and removes it. Results of the search are written in the variables. Variables are built according to the parameters in Table 1 . This variable used by the system as data source that will be displayed to the user.

Workflow system above can be illustrated in the following example:

1) The user enters a keyword to find students data with Student Identification for example 672008000.

2) System search student data with the keywords that entered. 


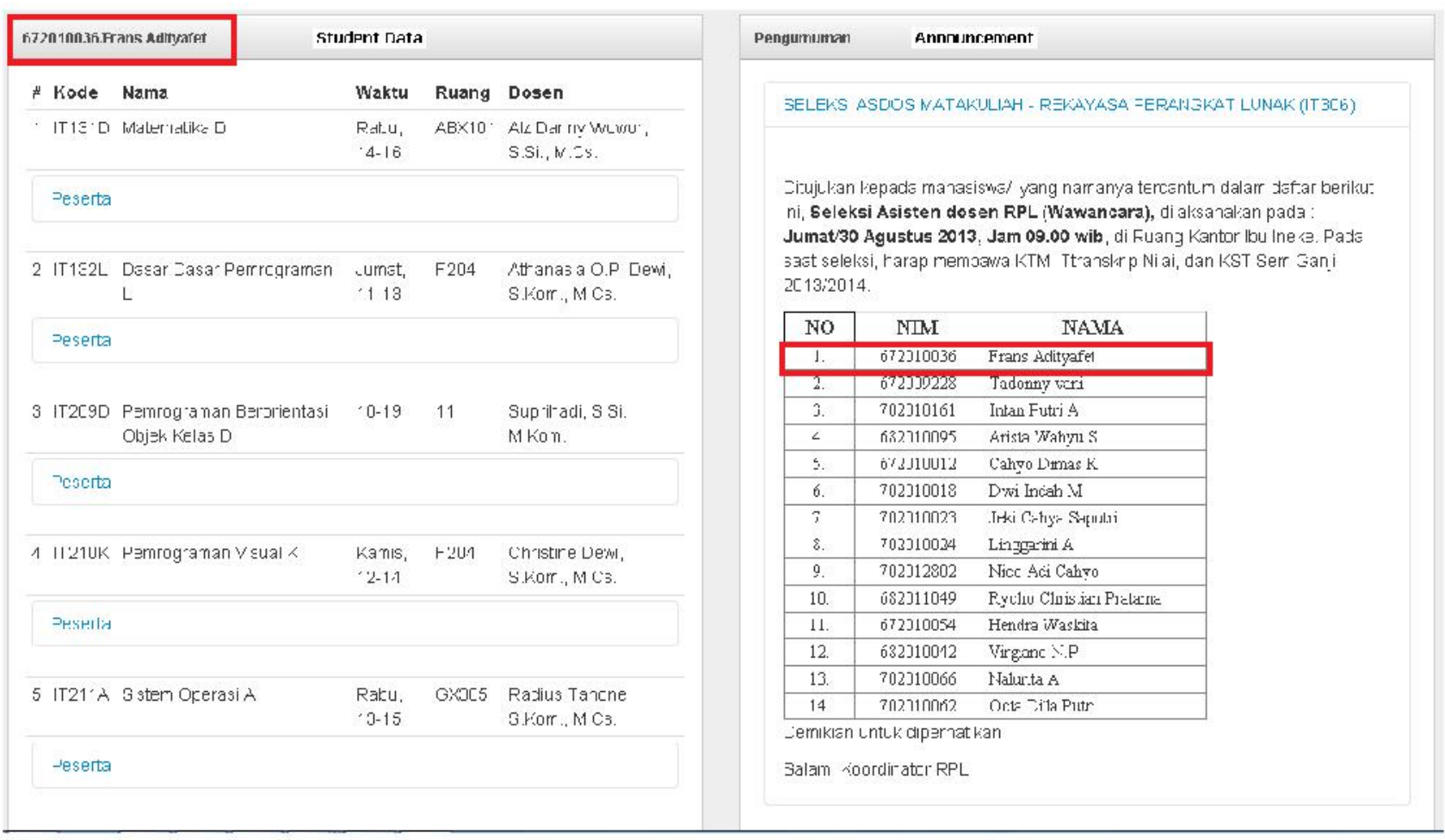

Figure 7. Mashups Results (After Mashup)

3) If the search results contain only 1 record, the system receives data contains NIM (Student Identification Number) and list of name of the courses. Otherwise, system displays a list of search results. Then the user chooses one of the search results.

4) Process continued with searching the website content which contains information about the search results. System search the data by comparing web content and the student data

5) System removes double data and write it into variables.

6) System displays the obtained data to user.

\subsubsection{Testing}

System testing conducted by entering name of the student as keywords used to search student data. From search results several student data is found in accordance with the keyword which entered as shown in figure 5. After that, the user selects one of the search results. The data selected by the user used by the system to search information contained in university website. Figure 7 shows the results of testing system.

\subsection{Experimental Results}

The results show that the system can provide information about students, course and lecturers along with information found on the website. The information displayed is the combination of two systems which used as data sources.

Data used in web mashups that developed is shown in Figure 4. There is a student class schedules consisting of code and name of the courses that are taken along with the code and the name of the lecturer. In each course there are some participants who registered. These course data used by the system as next keyword to search information contained in website. The information contained in website may contain Student Identification Number and name of students and also code or the name of course so that information can be used for comparison with students data.
Results displayed in Figure 7 shows the data obtained from SIASAT and faculty website. Student data such as NIM (student id), name and courses are used to find information in the website. The results obtained, the user can view information addressed to specific students.

From the experiment also found that there are data on the website in accordance with student data but not displayed. This is because the information on the website does not have uniformity in writing so the system unable to find out this information.

\section{Conclusion}

Using several services in a web application allows system to create an added value application. It allows developers to integrate service and data to provide new meaning services to the user.

The study produced a mashup application that helps the user, in this case students, to find information related to their course on the website which is used by lecturer or faculty as service announcements. The system collected data into single interface to facilitate students to find announcements aimed at these students.

\section{REFERENCES}

[1] Grifin, E. (2008). Foundations of Popfly : Rapid Mashup Development. New York: Apress.

[2] Benhaddi, M. (2012). A user-centric Mashuped SOA. International Journal Web Science, 204-223.

[3] Zeets, M. J. (2010). Web Mashups in the Supply Chain. Thesis for the degree of Master of Science in Technology at University of Kansas.

[4] Ozkan, N. (2010). Digging Social Networks by Mashups to Support Recruitment and Selection Functions in University Student Intake Process. IEEE International 
Workshop on Business Applications of Social Network Analysis .

[5] Gendarmi, D., \& Lanubile, F. (2009). A Web Mashup for Social Libraries. International World Wide Web.

[6] Kulathuramaiyer, N. (2007). Mashups: Emerging Application Development Paradigm for a Digital Journal. Journal of Universal Computer Science .

[7] Koschmider, A., Torres, V., \& Pelechano, V. (2009). Elucidating the Mashup Hype: Definition, Challenges, Methodical Guide and Tools for Mashups. Proceeding of 2nd Workshop on Mashups, Enterprise Mashups and Lightweight Composition on the Web.

[8] Baig, N. I., \& Bhatia, G. (2012). An introduction to Mashups and implementing Affiliate Marketing using Mashups. Proceedings published in International Journal of Computer Applications .

[9] Wong, J., \& Hong, J. (2008). What Do We "Mashup" When We Make Mashups? In Proceedings of the 4th International Workshop on End-User Software Engineering (pp. 35-39). New York: ACM.

[10] Pancardo, P., \& Wister, M. A. (2012). MAIZ: A Web Mashup Application for Information Services to CitiZens During Disaster Situations. International Journal of Computer Applications.
[11] Anjomshoaa, A., Bader, G., \& Tjoa, A. M. (2009). Exploiting Mashup Architecture in Business Use Cases. Proceedings of the 2009 International Conference on Network-Based Information Systems . USA.

[12] Sheong, C. S. (2008). Ruby on Rails Web Mashup Projects. Birmingham: Packt Publishing Ltd.

[13] Wilkinson, D. (2007). Flickr ${ }^{\mathrm{TM}}$ Mashups. Indianapolis, Indiana: Wiley Publishing, Inc.

[14] Patel, A., Na, L., Latih, R., Wills, C., Shukur, Z., \& Mulla, R. (2010). A Study of Mashup as a Software Application Development Technique with Examples from an End-User Programming Perspective. Journal of Computer Science , 1406-1415.

[15] Chatti, M. A., \& Jarke, M. (2011). Model-Driven Mashup Personal Learning Environments. International Journal of Technology Enhanced Learning .

[16] Salminen, A. (2013). Mashup Ecosystems: Integrating Web Resources on Desktop and Mobile Devices. Thesis for the degree of Doctor of Science in Technology at Tampere University of Technology.

[17] Yu, J., Benatallah, B., Casati, F., \& Daniel, F. (2008). Understanding Mashup Development. IEEE Internet Computing. 